\title{
Engineering of Recombinant Escherichia coli Towards Methanol Sensing Using Methylobacterium extroquens Two-component Systems
}

\author{
Vidhya Selvamani, Irisappan Ganesh, Sowon Chae, Murali kannan Maruthamuthu, and Soon Ho Hong* \\ Department of Chemical Engineering, University of Ulsan, Ulsan 44610, Republic of Korea
}

Received: August 20, 2019 / Revised: November 18, 2019 / Accepted: December 2, 2019

\begin{abstract}
Five genes ( $m x b D M, m x c Q E$ and $m x a B$ ) are responsible for the transcription of methanol oxidation genes in Methylobacterium strains. Among these, MxbDM and MxcQE constitute the two-component system (TCS) regulating methanol metabolism. In this study, we integrated the methanol-sensing domain of MxbD and MxcQ with the EnvZ/OmpR from Escherichia coli. The domain-swapping strategy resulted in chimeric histidine kinases (HK's) MxbDZ and MxcQZ AM1 containing recombinant E. coli. Real-time quantitative PCR was used to monitor OmpC expression mediated by the chimeric HK and response regulator (RR) OmpR. Further, an ompC promoter based fluorescent biosensor for sensing methanol was developed. GFP fluorescence was studied both qualitatively and quantitatively in response to environmental methanol. GFP measurement also confirmed ompC expression. Maximum fluorescence was observed at $0.05 \%$ methanol and $0.01 \%$ methanol using MxbDZ and MxcQZ AM1, respectively. Thus the chimeric HK containing $E$. coli were found to be highly sensitive to methanol, resulting in a rapid response making them an ideal sensor.
\end{abstract}

Keywords: Methanol, biosensor, chimeric two-component system, green fluorescent protein, Escherichia coli

\section{Introduction}

Methanol, one of the highly produced C1 compounds, also considered an alternative fuel. It is an additive and preservative in various products including processed foods, beverages, paints, coating products, and cosmetics. The versatility of methanol demands increased methanol production. Bioengineering of microbes could help in coping with methanol production cost-effectively. In addition, it is hard to sense methanol at lower concentrations, hence requiring a highly sensitive methanol sensing system. It could speed up the development of methanol producers. Two different methanol sensors grouped into physical and electrochemical [1] are used to

\section{*Corresponding author}

Tel: +82-52-259-1293, Fax: +82-52-259-1289

E-mail: shhong@ulsan.ac.kr

(c) 2020, The Korean Society for Microbiology and Biotechnology detect methanol. Although the above sensing systems are robust and reliable, the limited industrial usage roots from a lack of miniaturization [2]. It is a high time to develop a scalable system for high throughput sensing of methanol.

Bacteria ubiquitously sense environmental changes by a two-component system (TCS) [3, 4]. The TCS functions by coupling stimulus and response mechanisms using sensor kinase (SK) and response regulators (RR) $[4,5]$. Most of the SKs are periplasmic histidine kinase (HK); composed of a sensor, a linker, and a transmitter domain, respectively. Binding of a signal molecule with the sensor domain autophosphorylate transmitter domain further, donating the phosphate to RR. The phosphate bounded RR activates the of a control protein, which leads the transcription. Thus, the sensor domain plays a pivotal role in sensing the compounds present in the environment. A chimeric TCS constructed domain 
swap could help in engineering recombinant bacteria to sense desired compounds [6-15].

Methylotrophs are a group of bacteria that can use methanol as a sole source of carbon. It contains a wellestablished methanol sensing TCS. Methylobacterium extroquens are another group of methylotroph which can grow on multiple carbon sources like acetate, methanol (C1), ethanol, and ethylamine (C2), pyruvate (C3), or succinate (C4). Since methanol may play a major role as future alternative carbon sources $M$. extorquens has become a target for biotechnological applications [6]. It oxidizes methanol by enzymes methanol dehydrogenase and methylamine dehydrogenase [16]. Further methanol oxidation is regulated by $m x c Q E, m x b D M, m x a B$ [17-19] where $m x c Q E$ and $m x b D M$ are TCS with SK $(m x c Q, m x b D)$ and the RR $(m x c E, m x b M)$.

In previous studies our group has engineered HK from Paracoccous sp. into E. coli sense methanol. Considering the growing importance of Methylobacterium extroquens as $\mathrm{C} 1$ compound producers in our present study, we engineered chimeric HKs by integrating methanol sensing domain $m x b D$ from $M$. extroquens and $m x c Q$ AM1 from $M$. extroquens AM1. The EnvZ-OmpR is an extensively studied TCS it regulates the expression of outer membrane porins, $\mathrm{OmpF}$, and $\mathrm{OmpC}$, as an osmolarity change response. The resulting chimeric HK can sense extracellular methanol further donates phosphate group to the RR OmpR. It induces the expression of the ompC was quantified by real-time quantitative PCR (qRTPCR). OmpC promoter based fluorescent methanol sensor was developed. A Green fluorescent protein ( $g f p)$ gene was cloned under the control of ompC promoter (Fig. 1). The fluorescence was visualized and measured

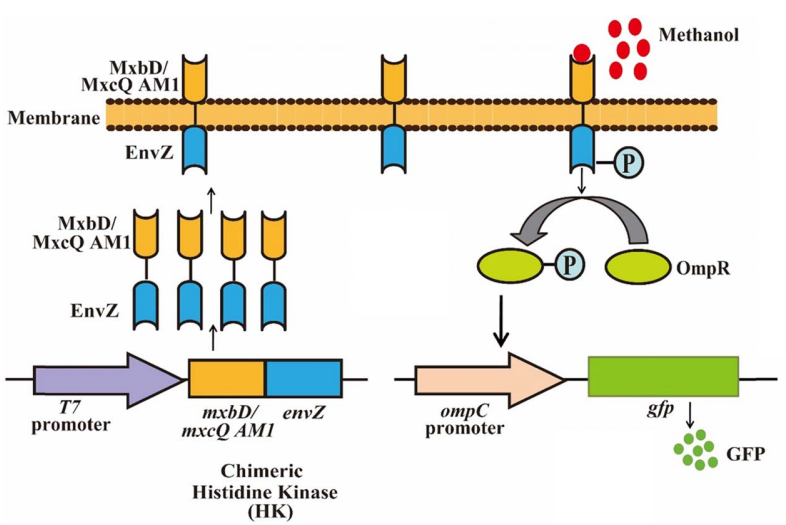

Fig. 1. E. coli engineered to respond to exogenous methanol. The M. extroquens periplasmic sensor kinase domain of MxbD/ MxcQ AM1 and the cytoplasmic catalytic domain of EnvZ was fused to form the MxbDZ/MxcQZ AM1 chimeric protein, which phosphorylates the response regulator OmpR of the TCS while senses methanol. This activates the ompC promoter, resulting in GFP expression in E. coli.

by microscopy and spectrofluorometer, respectively. The expression of GFP is considered as an active response of chimeric TCS (MxbDZ and MxcQZ AM1) towards methanol.

\section{Materials and Methods}

\section{Bacterial strains and growth conditions}

The bacterial strains for recombinant DNA manipulation and the expression of recombinant proteins were $E$. coli XL1-Blue (XB) and BL21 (DE3) respectively. The bacterial strains and plasmids used in this study are listed in Table 1. The strains were grown under constant shaking (250 rpm) in Luria-Bertani (LB) broth (10 g/l

Table 1. List of bacterial strains and plasmids used in this study.

\begin{tabular}{|c|c|c|}
\hline Strain/Plasmid & Relevant genotype and/or property & Source \\
\hline \multicolumn{3}{|c|}{ Escherichia coli strains } \\
\hline BL21 (DE3) & $F^{-}$ompT gal dcm lon hsdS ${ }_{B}\left(r_{B}{ }^{-} m_{B}{ }^{-}\right) \lambda(D E 3$ [lacl lacUV5-T7 gene 1 ind1 sam7 nin5]) & Novagen \\
\hline XL1-Blue & SupE44 hsdR17 recA1 endA1 gyrA96 thi relA1 lac $F^{\prime}\left(p r o A B^{+}\right.$lacl $1^{q}$ lacZLM15 Tn10 (tet $\left.\left.{ }^{R}\right)\right)$ & Stratagene \\
\hline \multicolumn{3}{|l|}{ Plasmids } \\
\hline pUC19 & $A m p^{R}$ & $\mathrm{NEB}^{\mathrm{a}}$ \\
\hline pOGFP1 & pUC19 containing the ompC promoter and $g f p$ gene, $A m p^{R}$ & {$[16]$} \\
\hline pACYCDuet-1 & $\mathrm{Cm}^{\mathrm{R}}$ & Novagen \\
\hline pMxbDZ & pACYCDuet- 1 containing the chimeric $m x c D$-env $Z$ gene, $\mathrm{Cm}^{\mathrm{R}}$ & This work \\
\hline pMxcQZ AM1 & pACYCDuet- 1 containing the chimeric $m x c Q$-envZ gene, $\mathrm{Cm}^{\mathrm{R}}$ & This work \\
\hline
\end{tabular}

aNew England Biolabs, U.S.A. 
bacto-tryptone, $5 \mathrm{~g} / \mathrm{l}$ bacto-yeast extract and $5 \mathrm{~g} / \mathrm{l} \mathrm{NaCl}$ ) and in M9 minimal salts medium (Sigma-Aldrich, USA) supplemented with $4 \mathrm{~g} / \mathrm{l}$ of glucose, $2 \mathrm{mM} \mathrm{MgSO}_{4}, 0.1$ $\mathrm{mM} \mathrm{CaCl} 2$ and $1 \%$ thiamine $\mathrm{HCl}$ at $37^{\circ} \mathrm{C}$.

\section{Molecular modeling of chimeric protein MxbDZ}

Molecular modeling was done to predict the optimal fusion site for chimeric sensor kinase (MxbDZ and MxcQZ AM1). Further the interaction between the methanol sensing and transmitter domain of the peptides was structurally investigated by molecular modeling. X-ray diffraction solved the three-dimensional structure of the EnvZ protein is available in the Protein Data Bank (PDB ID 4CTI) [20]. The homology model of EnvZ was fused with the peptide structure $(\mathrm{MxbD}$ and MxcQ AM1) modeled with 2JIN as a template by a graphical user interface program Easy Modeller 4.0 [21]. 3Drefine Protein Structure Refinement Server was used to refine the homology model [22].

\section{Chimeric SK construction}

Based on the computational studies, the chimeric SK (MxbDZ and MxcQZ AM1) was constructed. The periplasmic sensor domain of $m x b D$ (912 bp), $m x c Q$ AM1 (777 bp) and the cytoplasmic catalytic domain of envZ (684 bp) were amplified from the chromosomal DNA of $M$. extroquens and $E$. coli by polymerase chain reaction (PCR), respectively. PCR was performed with the MJ mini Personal Thermal Cycler (Bio-Rad, USA) using the Expand High Fidelity PCR system (Roche Molecular Biochemicals, Germany). The primers used in this study are listed in Table 2. The PCR products were cloned into the low copy number plasmid pACYCDuet-1 using SacI and HindIII restriction sites to construct the plasmids

Table 2. Oligonucleotide primers used in this study.

\begin{tabular}{ll}
\hline \multicolumn{1}{c}{ Name } & \multicolumn{1}{c}{ Sequence } \\
\hline MxbD_F_Sacl & 5'-GAGCTCATGAGATCTTTAAGAGTT-3' \\
MxbD_R_Pstl & 5'-CTGCAGCCGCCTGGAGCGGTCCAC-3' \\
MxcQ AM1_F_Sacl & 5'-GAGCTCATGGCTCAATCAGTGGCG-3' \\
MxcQ AM1_R_Pstl & 5'-CTGCAGATCGGATAATGCACCTGC-3' \\
EnvZ_F_Pstl & 5'-CTGCAGATCGGATAATGCACCTGC-3' \\
EnvZ_R_HindIII & 5'-AAGCTTTTACCCTTCTTTTGTCGTGCC-3' \\
OmpC_RT_Fwd & 5'-CTTCAAAGGTGAAACTCAGGTTACTG-3' \\
OmpC_RT_Rev & 5'-GTTGCCCTGGATCTGATATTCC-3' \\
\hline
\end{tabular}

pMxbDZ1 and pMxcQZ AM1. The expression of chimeric SK was induced by the addition of isopropyl $\beta$-D-1-thiogalactopyranoside (IPTG) regulated by the T7 promoter.

\section{ompC expression profile}

The dynamics of the chimeric TCS MxbDZ/OmpR and MxcQZ AM1/OmpR, towards ompC expression in response to varying concentrations of methanol (0-8\%) were measured by qRT-PCR. To perform qRT-PCR a single colony of $E$. coli BL21 (DE3) harboring pMxbDZ1 and pMxcQZ1 AM1 were cultured overnight in LB medium at $37^{\circ} \mathrm{C}$ was then diluted 100 -fold in fresh M9 medium and incubated at $37^{\circ} \mathrm{C}$ with vigorous shaking (250 rpm) until an optical density of 0.5 at $600 \mathrm{~nm}$ (OD600) reached. IPTG was added to the culture, and the cells were grown cultured at $30^{\circ} \mathrm{C}$ for $4.5 \mathrm{~h}$ in the presence of methanol. The cells were harvested by centrifugation for total RNA preparation using the RNeasy Mini kit (Qiagen) followed by DNase treatment.

Reverse transcription was performed with a cDNA synthesis kit (Applied Biosystems, USA) using a random hexamer primer mix according to the manufacturer's instructions. Specific primers were designed with OLIGO software (version 5.0; Molecular Biology Insights, USA) for quantitative expression of the ompC gene and 16sRNA (Supplementary Table 1). Samples for which the RT step was omitted were used as negative controls to ensure that the extracted RNA was not contaminated with DNA. The qRT-PCR reactions were performed on the Mini Opticon detection system using the SYBR Green PCR Master Mix as recommended by the manufacturer. Each qRT-PCR experiment was performed in triplicate using separate cultures grown under identical conditions $(n=3)$ and was calculated automatically by the Mini-Opticon software using 16s RNA as an internal control [23].

\section{gfp expression profile}

Recombinant $E$. coli harboring (pMxbDZ1, pMxcQZ1 AM1 and pOGFP1) were grown overnight and the cultures were diluted to 100 -fold in fresh M9 medium supplemented with appropriate antibiotics and incubated in an orbital shaker $(250 \mathrm{rpm})$ at $37^{\circ} \mathrm{C}$ until OD600 reached 0.5. Then $0.5 \mathrm{mM}$ IPTG was added to the culture medium and incubated with varying concentrations of methanol $(0-8 \%)$ at $30^{\circ} \mathrm{C}$ to induce the expression of the 
chimeric SK reported [13, 14, 18]. The strains were visualized for fluorescence with $100 \mathrm{x}$ objective on a reflected fluorescence microscope with a cooled, charge-coupled device camera (B\&W SenSys, KAF1401). Emission intensity was recorded using Meta-Morph image analysis software (Molecular Device, USA) with excitation and emission filter sets optimized for EGFP imaging [13, 14, 24]. Fluorescence were also quantitatively measured for the strains harboring chimeric SK at regular time intervals for $8 \mathrm{~h}$. Cell density was monitored by measuring the optical density at $600 \mathrm{~nm}$ with a spectrophotometer (Shimadzu, Japan). GFP fluorescence was measured using an RF-5301PC spectrofluorometer (Shimadzu), which was set at an excitation and the emission wavelength of $485 / 10$ and $515 / 10 \mathrm{~mm}$, respectively. The specific fluorescence intensity (SFI) was described as the raw fluorescence intensity expressed in relative fluorescence units divided by the optical density at $600 \mathrm{~nm}$ measured at regular time intervals [7, 13, 14, 24]. The measurements were performed at least in triplicate for each sample.

\section{Results and Discussion}

M. extroquens strains are methylotrophs, it is gaining more attention to produce value-added products from the single carbon (C1) compounds. The $\mathrm{C} 1$ compounds are metabolized methanol dehydrogenase and alcohol oxidase. The transcription of above genes was activated by five genes, it includes two TCS $m x b D M, m x c Q E$. TCS were exploited for the development of a fluorescence- based methanol sensor.

\section{Construction and expression of the chimeric SK MxbDZ \& MxcQZ AM1}

To engineer the methanol sensing TCS in E. coli a chimeric HK was constructed by fusing the methanol sensing domain mxbD and mxcQ AM1 from M. extroquens strains with the transmitter domain of $E$. coli envZ. As overexpression of membrane protein may cause destabilization of cell membrane. A low copy number plasmid pACYCDuet-1 was used in the construction of chimeric SK. Both the chimeric SK could methanol, sequentially activates the $\mathrm{RR}$ ompR and induces ompC expression. The ideal site for the construction of chimeric SK was evaluated by molecular modelling using the 3Drefine Protein Structure Refinement Server (Fig. 2). The colors magenta and blue indicate MxbD and EnvZ (Fig. 2A) subsequently, MxcQ AM1 and EnvZ are represented in blue and white respectively (Fig. 2B). The structural analysis revealed that more stable and active chimeric HK can be constructed by fusing the MxbD and MxcQ AM1 at the 305th and 254th methionine residue of EnvZ. Since methionine is considered as a hydrophobic amino acid, it tends to be buried inside the protein core results in a stable fused protein structure. The methyl group in methionine is connected to sulfur; hence the fusion does not intervene in the activity of chimeric SK $[13,14]$. Based on the modelling studies a recombinant plasmid was constructed (Figs. 3A and B). The overexpression of chimeric SK (MxbDZ and MxcQZ AM1) was carried out in varying concentration of IPTG and was
A

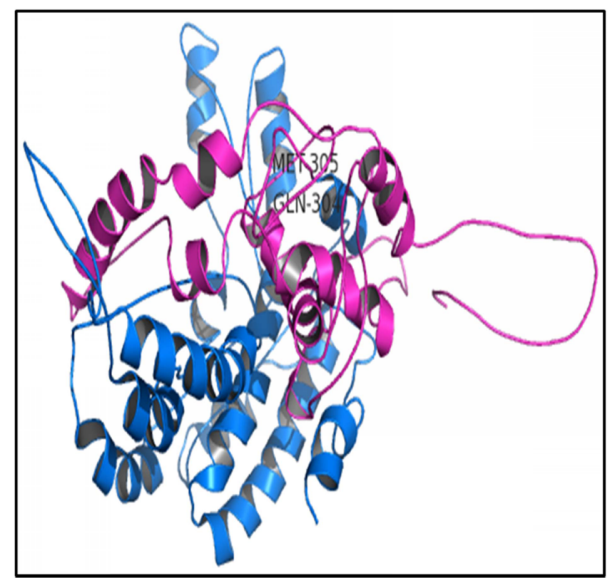

B

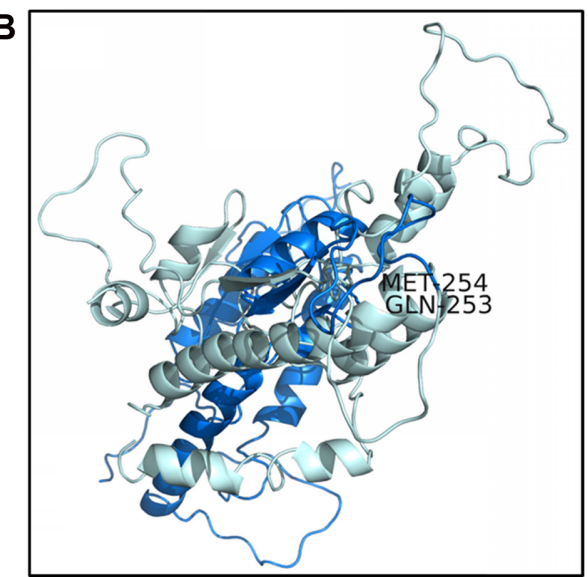

Fig. 2. Molecular modelling, image of chimeric SK (A) MxbD (Magenta) - EnvZ (Blue); (B) MxcQ AM1 (Blue) - EnvZ (White). 
A

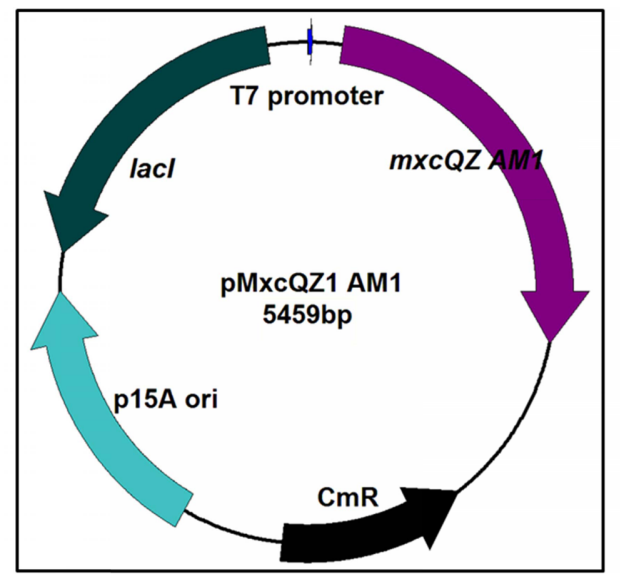

C

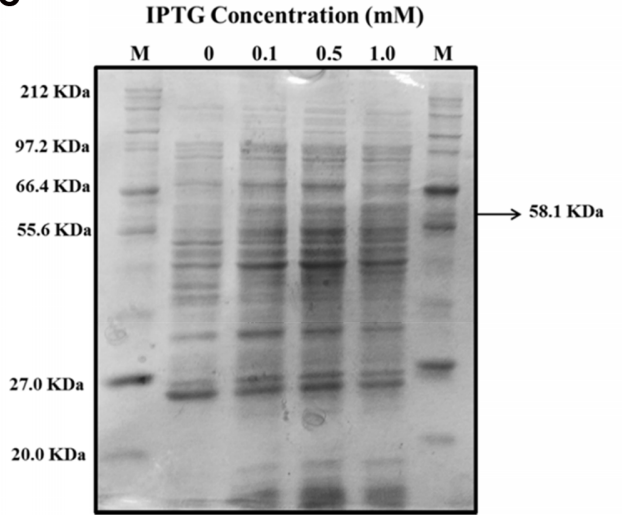

B

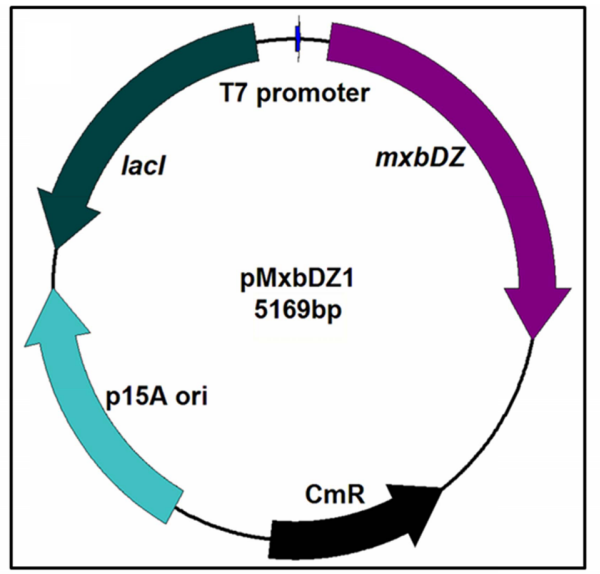

D

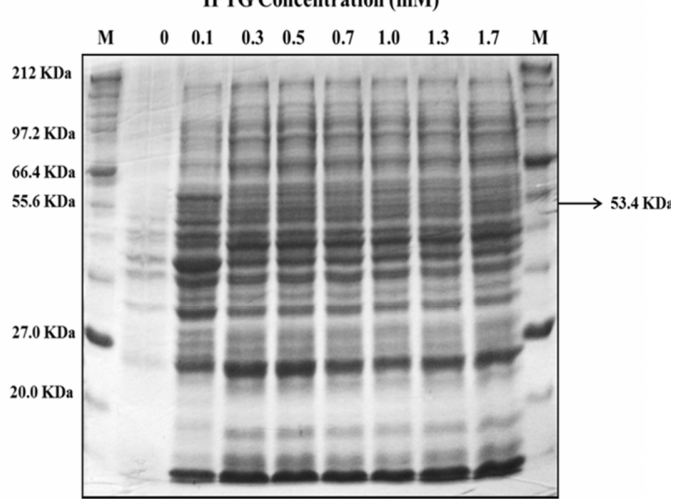

Fig. 3. Construction of recombinant plasmid with chimeric SK (A) pMxbDZ1, (B) pMxcQZ AM1; Recombinant protein expression analysis by SDS-PAGE (C) MxbDZ, (D) MxcQZ AM1; M. Molecular weight marker in KDa.

analysed by SDS-PAGE [25] (Figs. 3C and D). Both chimeric SK exhibited maximum expression at $0.5 \mathrm{mM}$ IPTG, with further increase the expression declined.

\section{ompC expression profile}

The expression of ompC mediated by MxbDZ/OmpR and MxcQZ AM1/OmpR was quantified by qRT-PCR (Figs. 4A-D). The recombinant $E$. coli were grown in minimal media supplemented with varying concentrations of methanol. In case of MXBDZ and MxcQZ AM1, maximum expression of $o m p C$ was at $2 \%$ and $0.01 \%$ of methanol respectively. It started to decline with further increase in methanol concentration. This might be due to the interruption of cellular activity and protein expression by methanol $[26,27]$. The correlation between methanol concentration and the relative transcriptional level was estimated to be 0.94592 (Figs. 4C and D). The expression of ompC can be considered as dynamic response of chimeric TCS towards extracellular methanol.

\section{gfp expression profile}

Expression of ompC was observed as a response to extracellular methanol. Based on the results we developed a fluorescent based methanol biosensor. To realize this, the $g f p$ was cloned downstream of the ompC promoter, which is activated by OmpR. The E. coli BL21 (DE3) strain harboring Chimeric SK (MxbDZ and MxcQZ AM1) and pOGFP1 was cultured with various concentrations of methanol. Time profiles showed that fluorescence increased as culture time increased. The control strain, harboring pACYCDuet-1 and pUC19, yielded a negligible amount of fluorescence (Figs. 5A-C). Though the IPTG inducer was not added, a low level of 

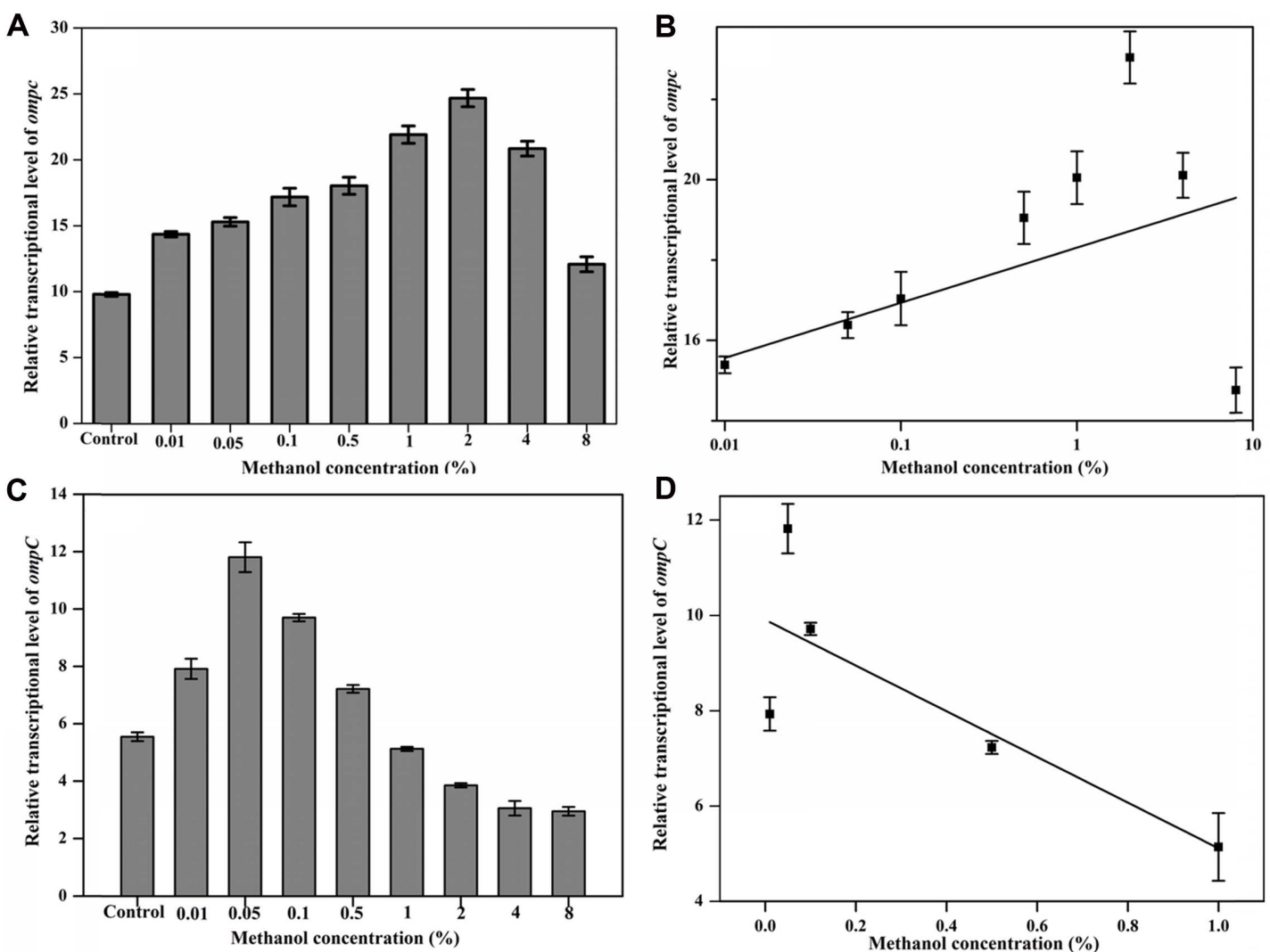

Fig. 4. Monitoring ompC expression by qRT-PCR; Comparative study of transcriptional levels of the ompC gene in the M9 medium after a $4.5 \mathrm{~h}$ exposure to methanol. E. coli harboring $(\mathrm{A}) \mathrm{pMxbDZ1}$ and $(\mathrm{C})$ pMxcQZ1 AM1 grown in the absence of methanol was included as the control; The linear correlation between the relative transcriptional levels of the ompCgene of the (B) pMxbDZ1 and (D) pMxcQZ1 AM1 in the M9 medium at varying concentrations of methanol. The data are the aggregate results from replicate experiments $(n=3)$.

fluorescence was observed, this might be due to the basal level of ompC promoter expression. Both chimeric TCS sensed as low as $0.01 \%$ methanol. After $8 \mathrm{~h}$ maximum fluorescence was observed at $0.05 \%$ and $0.01 \%$ with chimeric TCS MxbDZ and MxcQZ AM1 respectively. According to food and drug administration, the allowable limit of methanol into the environment is 200 ppm (0.02\%). Further increase in methanol resulted in a gradual decline in fluorescence. The GFP expression pattern of MxcQZ AM1 corroborates with the qRT-PCR results. In contrast with $\mathrm{MxbDZ}$ a shift in maximum fluorescence observed. According to qRT-PCR results maximum ompC expression was at $2 \%$ methanol. This may be due to the over-amplification of the GFP signal with the use of a high copy number-based reporter system (pOGFP1) [7]. This system could be employed to detect methanol in food and drinks as it is a commonly used preservative. Fluorescence was visualized by microscopy (Supplementary Fig. 1). The image clearly showed the ability of the constructed bacterial biosensor to detect environmental methanol and emit fluorescence as an output signal.

Methanol is used as an initial compound for various products including pharmaceutical products, LPG, gasoline, adhesives, automobiles, shopping bags, PET bottles, and mobile phones. The global market for methanol is expected to continue to rise because of its versatile applications. According to the methanol institute, over 90 methanol plants worldwide have a combined production capacity of 100 million metric tons per year. Considering the increasing demand for methanol, biotechnological strategies like metabolic engineering were employed to create cost-effective methanol producers. We strongly emphasize that with 

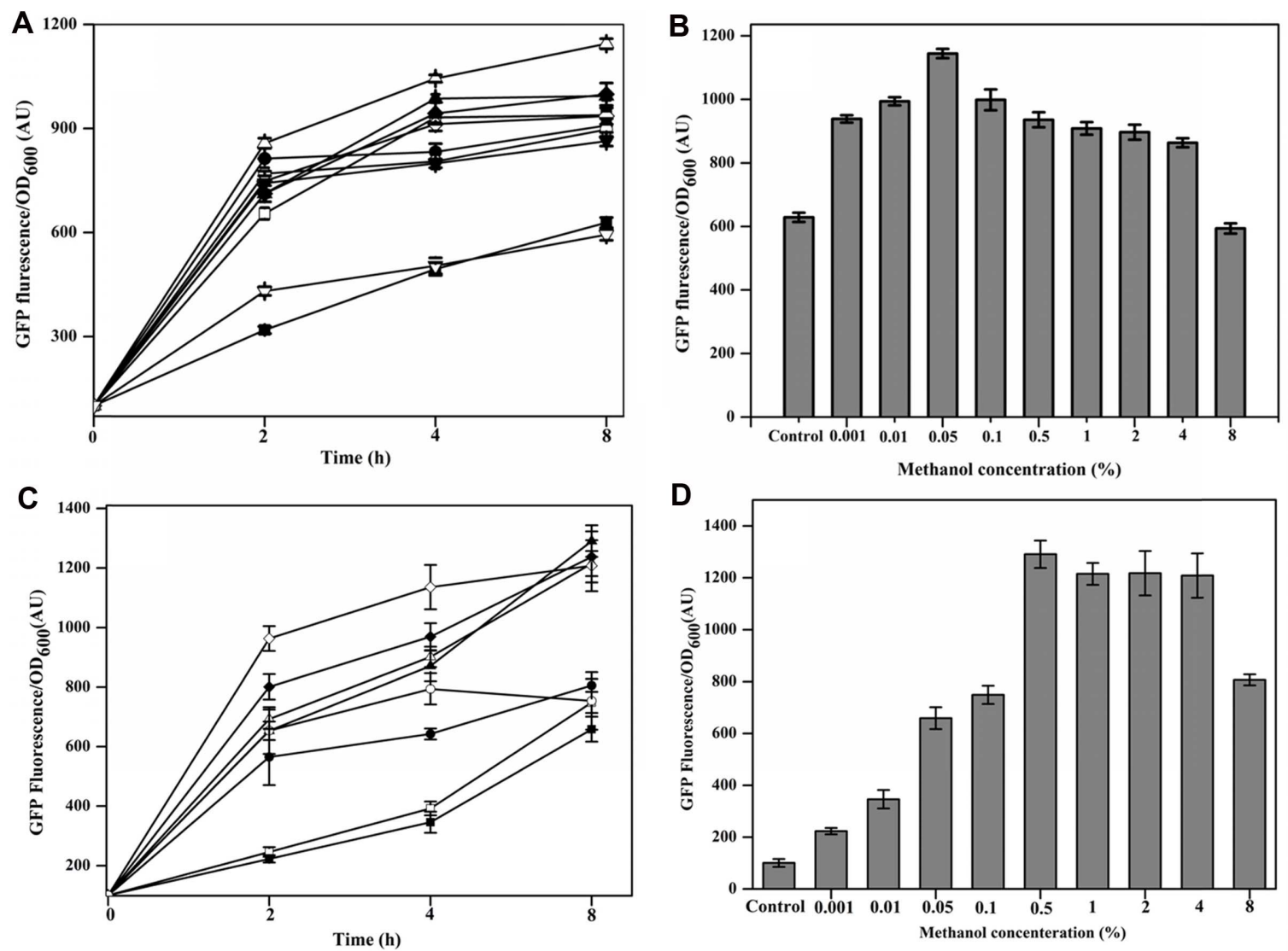

Fig. 5. Time course of GFP fluorescence for an E. coli strain harboring pMxbDZ1 (A), pMxcQZ1 AM1 (C) and pOGFP1 with varying concentrations of methanol in M9 medium. Control (closed square); $0.001 \%$ (Open square); $0.01 \%$ (closed upper triangle); $0.05 \%$ (open upper triangle); $0.1 \%$ (closed diamond); $0.5 \%$ (open diamond); $1.0 \%$ (closed circle); $2.0 \%$ (open circle); $4.0 \%$ (closed inverted triangle); $8.0 \%$ (open inverted triangle). The data are the aggregate results from replicate experiments ( $n=3$ ); GFP fluorescence value of $E$. coli strain harboring PMxbDZ1 and pOGFP1 after induction with and without varying concentrations of methanol in M9 medium after 8 hours of incubation (B) pMxbDZ1, (D) pMxcQZ1 AM1.

high-throughput methanol sensors, accelerated methanol production could be achieved. TCS based methanol sensors can sense and monitor desired compounds from the environment. In this study, the TCS from one of the ecologically relevant methylotrophs was engineered in E. coli by domain strategy. The resulting chimeric HK was able to produce an output signal in the form of fluorescence depending on environmental methanol concentrations.

\section{Acknowledgments}

This work was supported by Basic Science Research Program (2017R1D1A1B03032046) through the National Research Foundation of Korea (NRF) by the Ministry of Education.

\section{Conflict of Interest}

The authors have no financial conflicts of interest to declare.

\section{References}

1. Zhao H, Shen J, Zhang J, Wang H, Wilkinson DP, Gu CE. 2006. Liquid methanol concentration sensors for direct methanol fuel cells. J. Power Sources 159: 626-636.

2. Okada T, Nakamura N, Yuasa M, Sekine I. 1997. Ion and Water Transport Characteristics in Membranes for Polymer Electrolyte Fuel Cells Containing $\mathrm{H}^{+}$and $\mathrm{Ca}^{2+}$ Cations. J. Electrochem. Soc. 14: 2744-2750.

3. Laub MT, Goulian M. 2007. Specificity in two-component signal transduction pathways. Annu. Rev. Genet. 41: 121-145.

4. Stock AM, Robinson VL, Goudreau PN. 2000. Two-Component 
Signal Transduction. Annu. Rev. Biochem. 69: 183-215.

5. Mitrophanov AY, Groisman EA. 2008. Signal integration in bacterial two-component regulatory systems. Genes Dev. 22: 26012611.

6. Ganesh I, Ravikumar S, Lee SH, Park SJ, Hong SH. 2013. Engineered fumarate sensing Escherichia coli based on novel chimeric two-component system. J. Biotechnol. 168: 560-566.

7. Ganesh I, Ravikumar S, Yoo IK, Hong SH. 2014. Construction of malate-sensing Escherichia coli by introduction of a novel chimeric two-component system. Bioprocess Biosyst. Eng. 38: 797-804.

8. Utsumi R, Brissette R, Rampersaud A, Forst S, Oosawa K, Inouye M. 1989. Activation of bacterial porin gene expression by a chimeric signal transducer in response to aspartate. Science 245: 1246-1249.

9. Siryaporn A, Goulian M. 2008. Cross-talk suppression between the CpxA-CpxR and EnvZ-OmpR two-component systems in $E$. coli. Mol. Microbiol. 70: 494-506.

10. May T, Okabe S. 2008. Escherichia coli harboring a natural IncF conjugative $\mathrm{F}$ plasmid develops complex mature biofilms by stimulating synthesis of colanic acid and curli. J. Bacteriol. 190: 7479-7490.

11. Rogov VV, Rogova NY, Bernhard F, Koglin A, Löhr F, Dötsch V. 2006. A new structural domain in the Escherichia coli RcsC hybrid sensor kinase connects histidine kinase and phosphoreceiver domains. J. Mol. Biol. 364: 68-79.

12. Rizk SS, Cuneo MJ, Hellinga HW. 2006. Identification of cognate ligands for the Escherichia coli phnD protein product and engineering of a reagentless fluorescent biosensor for phosphonates. Protein Sci. 15: 1745-1751.

13. Selvamani V, Maruthamuthu MK, Arulsamy K, Eom GT, Hong SH. 2017. Construction of methanol sensing Escherichia coli by the introduction of novel chimeric MxcQZ/OmpR two-component system from Methylobacterium organophilum XX. Korean J. Chem. Eng. 34: 1734-1739.

14. Selvamani V, Ganesh I, Maruthamuthu MK, Eom GT, Hong SH. 2017. Engineering chimeric two-component system into Escherichia coli from Paracoccus denitrificans to sense methanol. Biotechnol. Bioprocess Eng. 22: 225-230.

15. Ganesh I, Selvamani V, Eom GT, Hong SH. 2017. Construction of methanol-sensing Escherichia coli by the introduction of a Paracoccus denitrificans mxaY-based chimeric two-component system. J. Microbiol. Biotechnol. 27: 1106-1111.

16. Chistoserdova L, Chen SW, Lapidus A, Lidstrom ME. 2003. Methy- lotrophy in Methylobacterium extorquens AM1 from a genomic point of view. J. Bacteriol. 185: 2980-2987.

17. Springer AL, Morris CJ, Lidstrom ME. 1997. Molecular analysis of $\mathrm{mxbD}$ and $\mathrm{mxbM}$, a putative sensor-regulator pair required for oxidation of methanol in Methylobacterium extorquens AM1. Microbiology 143: 1737-1744.

18. Xu HH, Janka JJ, Viebahn M, Hanson RS. 1995. Nucleotide sequence of the $\mathrm{mxcQ}$ and $\mathrm{mxcE}$ genes, required for methanol dehydrogenase synthesis in Methylobacterium organophilum XX: a two-component regulatory system. Microbiology 141: 25432551.

19. Vu HN, Subuyuj GA, Srividhya V, Good NM, Martinez-Gomez NC, Skovran E. 2016. Lanthanide-dependent regulation of methanol oxidation systems in Methylobacterium extorquens AM1 and their contribution to methanol growth. J. Bacteriol. 198: 1250-1259.

20. Baslé A, Rummel G, Storici P, Rosenbusch JP, Schirmer T. 2006. Crystal structure of osmoporin OmpC from E. coli at 2.0 Å. J. Mol. Biol. 362: 933-942.

21. Bhattacharya D, Cheng J. 2013. 3Drefine: Consistent protein structure refinement by optimizing hydrogen bonding network and atomic-level energy minimization. Proteins 81: 119-131.

22. Eswar N, Webb B, Marti-Renom MA, Madhusudhan MS, Eramian $D$, Shen MY, et al. 2007. Comparative protein structure modeling using MODELLER. Curr. Protoc. Protein Sci. Chapter 2:Unit 2.9.

23. Eleaume H, Jabbouri S. 2004. Comparison of two standardisation methods in real-time quantitative RT-PCR to follow Staphylococcus aureus genes expression during in vitro growth. J. Microbiol. Methods 59: 363-370.

24. Maruthamuthu MK, Ganesh I, Ravikumar S, Hong SH. 2015. Evaluation of zraP gene expression characteristics and construction of a lead $(\mathrm{Pb})$ sensing and removal system in a recombinant Escherichia coli. Biotechnol. Lett. 37: 659-664.

25. Laemmli UK. 1970. Cleavage of structural proteins during the assembly of the head of bacteriophage T4. Nature 227: 680-685.

26. Bourque D, Ouellette B, André G, Groleau D. 1992. Production of poly- $\beta$-hydroxybutyrate from methanol: characterization of a new isolate of Methylobacterium extorquens. Appl. Microbiol. Biotechnol. 37: 7-12.

27. Mayson BE, Kilburn DG, Zamost BL, Raymond CK, Lesnicki GJ. 2003. Effects of methanol concentration on expression levels of recombinant protein in fed-batch cultures of Pichia methanolica. Biotechnol. Bioeng. 81: 291-298. 